\title{
The Dynamic Visual Art Language of Architectural Landscape in the Context of New Media
}

\begin{abstract}
Wenxia Zhang ${ }^{1, *}$
${ }^{1}$ School of Fine Arts, Southwest University, Chongqing 400700, China

"Corresponding author. Email: jiaoyouzwx@qq.com

ABSTRACT

With the continuous innovation of scientific and technological means, the production of digital multimedia technology constantly impacts the traditional way of visual art communication. The expression form of architectural landscape design program changes from static drawings to dynamic images. Audio-visual combination replaces the previous single visual experience; the use of computer also gradually replaces the traditional paper. Dynamic renderings make architectural renderings no longer flat. These changes are inseparable from the spread of new media to a great extent. This paper discusses the concept of new media context and the characteristics of information transmission, and the characteristics and forms of architectural landscape dynamic visual art language in the context of new media. Finally, by consulting relevant literature, this paper summarizes the current application fields of architectural landscape dynamic visual art language. It is hoped that this paper will provide some ideas for the development of conceptual design of architectural landscape, and further deepen the development of dynamic visual arts language expression.
\end{abstract}

Keywords: new media, architectural landscape concept design, dynamic visual art language

\section{INTRODUCTION}

Visual language is a system composed of several visual symbols. With the development of new media means, dynamic visual language such as film animation is active in front of the screen. In the performance of architectural landscape concept design, this dynamic display not only saves time, but also increases the interest of the audience and obtains the recognition of the audience. Architectural designers can communicate the overall idea of the design scheme to the audience in a short period of time by means of $3 \mathrm{D}$ animation virtual software. Both sides can understand the building image through the dynamic architectural landscape visual language. Compared with other design methods, all of them only need to be completed with $3 \mathrm{D}$ virtual software on the computer, which saves a lot of drawings and hand painted time; performance is more realistic and perfect, in line with today's people's way of thinking and audience psychology. Thus, new media technology has brought convenience and infinite possibilities to the architectural landscape industry.

\section{THE DEFINITION AND CHARACTERISTICS OF NEW MEDIA CONTEXT}

\section{A. The concept of new media context}

New media refers to a new form of media produced with digital technology. Due to the changes of information Media and surrounding social environment in the society, the social structure is affected and has formed a special context and interpretation - new media context.

\section{B. The characteristics of information dissemination in the context of new media}

In the social environment of contemporary digital media, digital technology presents information to the public in a more convenient way. Due to the comprehensive use of computer technology, network and telecommunications, the process of information publishing to receiving presents a new form of communication. This process reduces the cost of information acquisition, which is convenient, efficient and fast. In addition, the information dissemination presents the interactivity. For example, information starts from the traditional one-way transmission to let the viewer to choose information independently, which is unable to be expressed by the traditional media. 


\section{THE PERFORMANCE CHARACTERISTICS OF DYNAMIC VISUAL ART LANGUAGE OF ARCHITECTURAL LANDSCAPE IN THE CONTEXT OF NEW MEDIA}

With the economic and social development, people also put forward higher requirements for art appreciation. In the concept design of architectural landscape, the dynamic visual art language shows many new features. For the performance of dynamic visual art, it is very different from the traditional art form. The traditional art form can not satisfy the requirement of people, which requires the creators to follow the trend of the times, and innovate the existing forms, so that art and the times blend each other.

\section{A. Virtual reality}

In the context of new media, designers can use digital media technology to build a virtual space for architectural activities. Under the action of 3D technology, the way of presenting through dynamic virtual visual image will make the unfinished architectural landscape design plan to the public. Under the effect of audio-visual languages, dynamic 3D technology can break through the limitations of static pictures in traditional media, and express the overall concept of conceptual design from multiple perspectives, break the limitations, make the whole scheme more vivid and attract the attention of the audience.

\section{B. Integration of technology and art}

With the continuous development of computer technology, it is far from enough to rely solely on technology for the conceptual design of architectural landscapes. The creator should make a bold breakthrough in the form. This requires them to understand current trend and integrate contemporary art, making the dynamic object and art blend with each other. In addition, designers should not be limited to the part of dynamic objects. In order to realize the division, we should grasp the overall situation of the details and the whole displayed in the conceptual design. We should look at the design from a broader perspective to produce a unified beauty, and then gradually transform the abstract content, and finally form intuitive visual dynamic content. This expression is more clear and helpful to the audience's understanding.

\section{Diversified comprehensive communication}

With the help of new media methods, we have achieved audio-visual integration. For example, text, sound, and pictures can be integrated in one space to achieve the effect of dynamic presentation of architectural space. Dynamic architectural landscape renderings can present the concept of design scheme more vividly and concretely, and let people understand the general situation of the project more intuitively. It is the optimization of the architectural plan under the traditional media before, and has the advantage of keeping up with the times.

\section{Sequence}

With the dynamic display of architectural landscape concept design, the dynamic pictures that people see are composed of lens language, and these shots are arranged and combined orderly by the creator according to the design ideas and process of the scheme. The time of appearance of the buildings in the picture or the order between the pictures need to be determined in advance by the architect and designer. Usually, the order of architectural animation reflects the requirements of creators who want to show the design concept. At the same time, these sequences can also reflect the lively and interesting buildings in dynamic display, and can increase the interest of viewers according to the arrangement of order.

\section{ELEMENTS OF DYNAMIC VISUAL ART LANGUAGE OF ARCHITECTURAL LANDSCAPE IN THE CONTEXT OF NEW MEDIA}

\section{A. Lens language}

For architectural animation, the lens language is the most basic component. The lens language is equivalent to the mouth of your picture. Through the lens language, the viewer can easily understand the entire picture. Sometimes it is difficult for a single shot to explain the content of the screen. It is necessary to edit each shot reasonably to construct the story content together.

\section{B. Scene}

From the perspective of shooting, scene category refers to the scope that can be observed by the camera. In the perspective of the object to be photographed, it refers to the size of the part of the object to be photographed in the picture. Its size is determined by the distance between the camera and the subject. Usually, we divide the scene into several definitions, such as close-up, close range, medium range, panorama, and long-range. Each scene does not exist independently. They all communicate with each other to complete each shot. The standard of each scene is defined by the imaging range of the subject in the frame.

\section{Light}

Light is a very important role in architectural animation. From a physical point of view, imaging cannot be formed without light. Only under the action of light can the black-and-white relationship of the picture be formed, and the subject will have a sense of 
volume. In the audiovisual language analysis process of animation, the analysis of light is very important. It can directly set off the atmosphere. The actual use of light mainly involves its relative intensity, direction, area, color and other properties. The contrast is different when the intensity of light is different, which directly brings visual contrast and contrast to the audience and enhances the depth of the picture. Each use of light must be analyzed and figured out according to the actual situation in order to maximize its effect.

\section{Tone}

The tone of the picture in animation is the layered sense of light and shade formed by the effect of light. It can be divided into hard tone and soft tone. The socalled hard tone picture has strong contrast of light and shade, and the theme is prominent. Soft tones tend to have weaker color pairs, and the picture effect presents a soft and concise effect. Different colors will bring different visual experience to people. In use, we should choose $\mathrm{J}$ according to the theme of creation.

\section{E. Color}

Color enriches the environment around us. It is a kind of energy radiation. Different colors have different energy and different effects on people.

\section{APPLICATION OF DYNAMIC VISUAL ART LANGUAGE OF ARCHITECTURAL LANDSCAPE IN THE CONTEXT OF NEW MEDIA}

For the architectural landscape conceptual design, the way of dynamic visual display ranges from $\mathrm{ppt}$ dynamic pictures to three-dimensional roaming animation, and finally to the current architectural animation demonstration, and the way of information transmission is constantly updated. In the short span of a few years from the end of the 20th century to the beginning of the 21 st century, China's construction industry was also the most prosperous period. The civil engineering market and the real estate market were very prosperous. As the market expanded, the demand in various aspects also increased. Since then, the demand for architectural renderings has increased, and companies that produce professional drawings have begun to appear. Promoted by computer technology, simple renderings have been overwhelming. In order to occupy the market, individual rendering companies began to produce simple architectural animation videos to better serve the real estate industry and obtain greater profits. Since then, architectural animation has appeared. We believe that through free observation of the architectural animation lens in all directions, the overall future effect of the building can be fully and truly displayed. It can capture the lens that the camera can' $t$ achieve in real shooting, and interpret the thoughts of the architect design masters in a perfect and artistic image. At the same time, it can also make people feel a beautiful future home. Architectural animation is a product of architectural design. Using architectural three-dimensional animation, we can visualize the geographical environment, appearance and interior of the building in a visual and dynamic way during the design phase of the building, and finally achieve a smooth and unobstructed effect. Decoration, function, space and other facilities enable people to wander in the wonderful buildings of the future. Because it has become a powerful tool for the display of architectural design plans and decoration effects, with the continuous advancement of computer technology, the architectural field is constantly being updated. Dynamic visual art is not only one-way spread to viewers, but also begins to turn Interactive, immersive experience, there is no doubt that it has increasingly broad application prospects in the architectural design industry, real estate industry and building decoration industry. At present, it is mainly used in the following areas:

\section{A. Real estate animation}

The real estate industry is the first industry to utilize the dynamic display of architectural landscapes. It is the process of turning future housing and commercial buildings from zero into reality. Through the display of dynamic architectural landscape design schemes, customers can understand the design concept, generation process and architectural appearance of future houses, and the three-dimensional technology will make the architectural renderings very realistic. This dynamic display method not only saves manpower and material resources, but also attracts the interest of customers. At the same time, it has also invisibly increased the number of house transactions, so it has become the main sales method for real estate developers.

\section{B. Construction bidding}

Construction bidding is a very common commercial activity in the market. It is mainly aimed at some largescale construction projects. The design ideas of the early design company bidding projects are only shown in a few design drawings, and Party A cannot read the drawings. When displaying the details of the design concept, the dynamic presentation of the architectural landscape is adopted, which can transform the traditional painting into dynamic line movement, and then the static visual language becomes the dynamic visual art language, which greatly increases the viewers interest of.

\section{Urban planning and publicity}

The city embraces each of us like a big family, and the development of the city is also a concern for everyone. Nowadays, using dynamic visual display 
instead of the previous paper-and-pencil planning concept, the city's construction process and future development plan are animated, so that everyone can see the future of the city, and cherish life while lamenting technology.

\section{The restoration of ancient buildings}

my country is rich in historical and cultural resources, as well as splendid ancient buildings and ancient civilizations. However, due to historical reasons, many famous ancient buildings have shown signs of damage. Using three-dimensional technology to collect the appearance of the building and access data, the restoration of the ancient building is displayed in a dynamic visual art way, so that everyone can appreciate the beauty of history.

\section{E. Games and film and television}

With the continuous development of the information age, the technological content of the game industry and the film and television industry is getting higher and higher. The game is shifting from two-dimensional performance to three-dimensional virtual space.And the completion of some special effects shots in movies and $\mathrm{TV}$ is also connected with three-dimensional dynamic technology.

\section{CONCLUSION}

Dynamic visual performance refers to the generation process of the whole architectural landscape conceptual design. Using dynamic can make the audience see the concept of the whole scheme more conveniently. From the beginning of the drawing to the final effect drawing, the viewer can see the detailed design process. It's not just about the final partial rendering of the design. It's the previous dynamic refactoring and optimization.

As a new communication method in the current information age, new media will inevitably penetrate into all aspects of society. The connotation and form of the dynamic visual art expression language of architectural landscapes are not static. It will continue to introduce new ones with the development of the times. Presenting new artistic connotations, thinking and expression methods, and bringing people a new visual perception, visual impact and imagination space, the future architectural landscape conceptual design will inevitably become more diversified.

\section{References}

[1] Zhu Qi, "new media art in the late 20th century," Beijing: China Renmin University Pres, 2005.

[2] Li Jun, "dynamic media design: from interface composition to four-dimensional creativity", Shanghai People's fine arts press, 2005.
[3] Lu Jian, "dynamic visual art expression in digital media interface", Media Forum, Vol. 3, No. 17, pp. 174, 2020.

[4] Zhu Hui, "audio visual language and animation sub lens", Beijing: Tsinghua University Press, 2009.

[5] Guo Daorong, "Art aesthetics", Sichuan: Sichuan Fine Arts press, 2006.

[6] Peng Chao, Zhang Guohua, Qi Yu, "architectural animation-3D Max production", Beijing: Tsinghua University Press, 2011. 